\title{
Differences between the rhizosphere microbiome of Beta vulgaris ssp. maritima-ancestor of all beet crops-and modern sugar beets
}

\author{
Christin Zachow ${ }^{1,2 *}$, Henry Müller ${ }^{2}$, Ralf Tilcher ${ }^{3}$ and Gabriele Berg ${ }^{2}$ \\ 1 Austrian Center of Industrial Biotechnology (AClB GmbH), Graz, Austria \\ 2 Institute of Environmental Biotechnology, Graz University of Technology, Graz, Austria \\ ${ }^{3}$ KWS SAAT AG, Einbeck, Germany
}

\author{
Edited by: \\ Kornelia Smalla, Julius Kühn-Institut, \\ Federal Research Centre for \\ Cultivated Plants, Germany \\ Reviewed by: \\ Kornelia Smalla, Julius Kühn-Institut, \\ Federal Research Centre for \\ Cultivated Plants, Germany \\ Weixing Shan, Northwest A\&F \\ University, China \\ Yusuke Saijo, Max Planck Institute \\ for Plant Breeding Research, \\ Germany \\ ${ }^{*}$ Correspondence: \\ Christin Zachow, Institute of \\ Environmental Biotechnology, Graz \\ University of Technology, \\ Petersgasse 12/1, Graz 8010, Austria \\ e-mail: christin.zachow@tugraz.at
}

The structure and function of the plant microbiome is driven by plant species and prevailing environmental conditions. Effectuated by breeding efforts, modern crops diverge genetically and phenotypically from their wild relatives but little is known about consequences for the associated microbiota. Therefore, we studied bacterial rhizosphere communities associated with the wild beet $B$. vulgaris ssp. maritima grown in their natural habitat soil from coastal drift lines (CS) and modern sugar beets (Beta vulgaris ssp. vulgaris) cultivated in CS and potting soil (PS) under greenhouse conditions. Analysis of $16 \mathrm{~S}$ rRNA gene fingerprints and pyrosequencing-based amplicon libraries revealed plant genotype- and soil-specific microbiomes. Wild beet plants harbor distinct operational taxonomic units (OTUs) and a more diverse bacterial community than the domesticated sugar beet plants. Although the rhizospheres of both plant genotypes were dominated by Proteobacteria and Planctomycetes, $37.5 \%$ of dominant OTUs were additionally detected in the wild beet rhizosphere. Analysis of the cultivable fraction confirmed these plant genotype-specific differences at functional level. The proportion of isolates displayed in vitro activity against phytopathogens was lower for wild beet $(\leq 45.8 \%)$ than for sugar beet $(\leq 57.5 \%)$. Conversely, active isolates from the wild beet exhibited stronger ability to cope with abiotic stresses. From all samples, active isolates of Stenotrophomonas rhizophila were frequently identified. In addition, soil type-specific impacts on the composition of bacterial communities were found: Acidobacteria, Chloroflexi, and Planctomycetes were only detected in plants cultivated in CS; whereas Bacteroidetes and Proteobacteria dominated in PS. Overall, in comparison to modern sugar beets, wild beets were associated with taxonomically and functionally distinct microbiomes.

\section{Keywords: wild beet, sea beet, sugar beet, rhizosphere, antagonistic bacteria, stress protecting bacteria}

\section{INTRODUCTION}

The domestication of plants began with the identification of wild plant species exploitable for food, animal feed, or other domestic purposes. Selective crop breeding programs are mainly oriented toward increasing food production and high-yielding varieties, percentage of usable plant parts, and resistance against diseases (Akhalkatsi et al., 2012). The genetic background of sugar beet is narrower compared to other crops because the sugar beet breeding had started in the late eighteenth century when lines accumulating sugar in the storage root were selected from crosses made with chard and fodder beet (Fischer, 1989). In contrast to many other crops, the ancestor of domesticated sugar beets (Beta vulgaris ssp. vulgaris $\mathrm{L}$.) is known and still distributed throughout Europe, especially in the Mediterranean region along coastal drift lines. The genome of the wild form B. vulgaris L. ssp. maritima (L.) Arcang. (trivial name: wild or sea beet) differs significantly from domesticated sugar beet lines (Dohm et al., 2014). For example, it shows high variation at the vernalization $B$-locus, and therefore most of the plants are perennials in contrast to all cultivated lines, which have a biennial life cycle enabling seed production (Dohm et al., 2014). Today, modern sugar beet cultivars that accumulate enormous amount of sugar are of importance, not only for commercial sugar production, but also as renewable resource, e.g., for bioethanol production (Dodić et al., 2009). Although several studies analyzing sugar beet-associated bacterial communities already exist (Zachow et al., 2008; Mendes et al., 2011; Shi et al., 2014), little is known about the relation of the microbiome to existing cultivars and their wild relatives.

Plants have recently been recognized as meta-organisms, due to a close symbiotic relationship with their microbiome. Comparable to humans and other eukaryotic hosts, plants also harbor a "second genome" that fulfills important host functions including protection against biotic and abiotic stress (Berendsen et al., 2012; Berg et al., 2013). Interestingly, plant-associated 
bacteria derived from different origins. Microorganisms can be transmitted by pollen and seeds (Fürnkranz et al., 2012); the latter was also shown for sugar beet (Dent et al., 2004). However, specific microorganisms are enriched from the surrounding environment as well, e.g., attracted by root exudates containing carbohydrates, proteins, and vitamins (Chaparro et al., 2013). In result of these processes, each plant harbors to a certain degree specific microbes (rev. in Berg and Smalla, 2009; Bulgarelli et al., 2012). This specificity was also shown for the plantassociated microbiome at cultivar level, e.g., for rice (Engelhard et al., 2000; Hardoim et al., 2011) as well as for maize (Haichar et al., 2008; Philippot et al., 2013). The evolutionary relationship in wheat-microorganism interactions was revealed already by Germida and Siciliano (2001); ancient wheat cultivars were colonized by phylogenetically diverse rhizobacterial isolates, whereas the rhizosphere of modern cultivars was dominated by fastgrowing Proteobacteria. Therefore, we developed the hypothesis that the microbiome of the wild beet harbors a high degree of specific microorganisms in comparison to the sugar beet crop. We expected this degree of specificity also for the functions of the associated bacteria. The wild beet plants commonly grow in salinated dune soil of coastal drift lines. Thus, protection against abiotic stress by the microbiome should be more important than against biotic stress because plant diseases are not known for these populations (Biancardi et al., 2012). As reason for the specific microbiome of the wild beet, we assumed not only the genetic background of the wild ancestor; we also hypothesized an impact of the microbiome of the coastal drift line soil.

The objective of this study was: to determine key players in the rhizosphere microbiomes of (i) wild beet plants grown in coastal drift line soil (WB-CS), and (ii) domesticated sugar beets cv. BERETTA (SB) in dependence of the soil type (coastal drift line soil, CS, and potting soil, PS), and (iii) to determine the potential of isolates to cope with biotic and abiotic stresses in successive screenings.

\section{MATERIALS AND METHODS SAMPLING AND EXPERIMENTAL DESIGN}

Wild beet plants (WB) with the synonymous common name sea beet [B. vulgaris ssp. maritima (L.) Arcang.] were sampled from the drift line at the Mediterranean Sea coast in Slovenia (N 45.590725, E 13.719469). Along a $200 \mathrm{~m}$ coastal drift line, four independent samples were taken. On average, plants were $20 \mathrm{~cm}$ high. Leaves were unfolded and separately spread on the beet heads without flower buds or seed development. Additionally, we collected coastal drift line soil (CS, pH 9.5, electric conductance $\mathrm{S}=1728 \mu \mathrm{S} \mathrm{cm}^{-1}$ ) from the layer of $0-10 \mathrm{~cm}$ depth. Samples were placed into sterile plastic bags and transported to the laboratory at $4^{\circ} \mathrm{C}$. Commercial sugar beet (SB) seeds cv. BERETTA KWS were provided by KWS SAAT AG (Einbeck, Germany). Seeds (10 per pot) were planted in a potting bulk soil (PS, soil:sand:vermiculite mixture 3:1:1, potting soil basis: "Gramoflor Profi-Substrat-Topfpikier M+Ton+Fe," GBC, Kalsdorf, Austria, $\mathrm{pH}\left(\mathrm{CaCl}_{2}\right) 5.8$, electric conductance $\mathrm{S}=1330 \mu \mathrm{S} \mathrm{cm}{ }^{-1}$, containing white and black peat with $90 \mathrm{~kg} \mathrm{~m}^{-3}$ moist clay, $1.0 \mathrm{~kg}$ $\mathrm{m}^{-3}$ PG-Mix (Greenworld, Wels, Austria), $50 \mathrm{~g} \mathrm{~m}^{-3}$ Radigen $^{\circledR}$ (Terraflor, Iserlohn, Germany); sand: “Maxs Spielsand ${ }^{\circledR}$," Scherf
GmbH \& Co KG, Hartberg, Austria; vermiculite: "Verm 3-6 mm," Ratioform, Vienna, Austria) as well as in coastal bulk soil from the drift line (CS). For SB-PS, five replicates, and for CS-due to the limited amount of available soil and plant materialthree (SB-CS) replicates were incubated under greenhouse conditions ( $12 \mathrm{~h}$ light/dark at $18^{\circ} \mathrm{C}, 60 \%$ humidity) for 2 weeks. To isolate microorganisms, $20 \mathrm{~g}$ of roots with adhering soil were mixed with $50 \mathrm{ml}$ sterile $0.85 \% \mathrm{NaCl}$ for $3 \mathrm{~min}$ in a laboratory blender (BagMixer, Interscience, Mourjou, France). Suspensions were used for cultivation-independent and -dependent analyses. Samples were labeled as follows: CS — coastal drift line soil, PS - potting soil, SB-CS — sugar beet plants cultivated in coastal drift line soil, SB-PS - sugar beet plants cultivated in potting soil, WB-CS — and wild beet plants grown in coastal drift line soil.

\section{MOLECULAR FINGERPRINTS OF 16S rRNA GENES}

For cultivation-independent analyses, $8 \mathrm{ml}$ of the above mentioned suspension were centrifuged at high speed $(16,000 \times \mathrm{g}$, $4^{\circ} \mathrm{C}$ ) for $20 \mathrm{~min}$ and the resulting microbial pellets were stored at $-70^{\circ} \mathrm{C}$ until further processing. Total DNA of the rhizosphere communities were extracted by mechanical disruption and homogenization of the pellet using FastDNA Spin Kit for Soil and a FastPrep Instrument (MP Biomedicals, Illkirch, France) for $30 \mathrm{~s}$ at $5.0 \mathrm{~m} \mathrm{~s}^{-1}$. DNA was additionally purified by the GeneClean Turbo Kit (MP Biomedicals, Illkirch, France) containing guanidine thiocyanate to remove humic acids. Extracted DNA was treated with RNase $\left(0.02 \mathrm{ng} \mu \mathrm{l}^{-1}\right)$ for $5 \mathrm{~min}$ at $65^{\circ} \mathrm{C}$ to obtain the template for PCR amplification of $16 \mathrm{~S}$ rRNA genes from total community DNA.

Single strand conformation polymorphism (SSCP) analysis was carried out according to Schwieger and Tebbe (1998) using a $8.0 \%$ polyacrylamide gel running $26 \mathrm{~h}$ for bacterial community analysis at $400 \mathrm{~V}$. SSCP-PCR was performed according to Köberl et al. (2011). Gels were transmissively scanned (Epson perfection 4990 Photo, Nagano, Japan) to obtain digitized gel images. Normalization and cluster analysis of band patterns, evaluated on band intensity, were carried out with the GelCompar II program (Applied Maths, Sint-Martens-Latem, Belgium). The cluster analysis was performed using the following settings: dendrogram type: unweighted pair group method with arithmetic mean (UPGMA); curve based similarity coefficient: Pearson correlation; optimization $4 \%$, and position tolerances $1 \%$. Background correction was applied for each track. The Pearson correlation index for each pair of lanes within a gel was calculated as a measure of similarity between the community fingerprints.

\section{AMPLICON PYROSEQUENCING AND BIOINFORMATIC ANALYSIS}

The hypervariable V4-V5 region of the 16S rRNA gene (Escherichia coli positions 515-927) was amplified in a nested PCR approach for 454 pyrosequencing to analyze the taxonomic composition of the bacterial rhizosphere community. The first PCR was conducted with the primer pair 27f/1492r (Lane, 1991), while the second PCR targeted the V4-V5 region with the primer set that contained the 454 pyrosequencing adaptors and samplespecific tags (Table S1). The reaction mixture for the first PCR $(10 \mu \mathrm{l})$ contained $1 \times$ Taq\&Go (MP Biomedicals, Eschwege, 
Germany), $0.1 \mu \mathrm{M}$ of each primer and $1 \mu \mathrm{l}$ of template DNA $\left(95^{\circ} \mathrm{C}\right.$ for $5 \mathrm{~min}, 30$ cycles of $95^{\circ} \mathrm{C}$ for $30 \mathrm{~s}, 57^{\circ} \mathrm{C}$ for $30 \mathrm{~s}, 72^{\circ} \mathrm{C}$ for $90 \mathrm{~s}$, and elongation at $72^{\circ} \mathrm{C}$ for $5 \mathrm{~min}$ ). The second PCR $(60 \mu \mathrm{l})$ was performed by using $1 \times$ Taq\&Go, $1.5 \mathrm{mM} \mathrm{MgCl}$, $0.1 \mu \mathrm{M}$ of each primer and $3 \mu \mathrm{l}$ of first PCR template $\left(95^{\circ} \mathrm{C}\right.$ for $5 \mathrm{~min}, 32$ cycles of $95^{\circ} \mathrm{C}$ for $20 \mathrm{~s}, 54^{\circ} \mathrm{C}$ for $15 \mathrm{~s}, 72^{\circ} \mathrm{C}$ for $30 \mathrm{~s}$, and elongation at $72^{\circ} \mathrm{C}$ for $10 \mathrm{~min}$ ). PCR products of four replicates per samples of the same habitat were pooled in equal molarities and purified with the Wizard ${ }^{\mathrm{TM}}$ SV Gel and PCR CleanUp System (Promega, Madison, USA). 16S rRNA gene amplicons were pyrosequenced with Roche 454 FLX GS conducted by MWG Biotech (Ebersberg, Germany). De-multiplexed raw sequences were processed using the open source software package QIIME (release 1.8.0; Caporaso et al., 2010). Prior to denoising (Reeder and Knight, 2010) sequences were quality (minimum average quality score in reads: 25) and length filtered (430450 bp). Chimeric sequences were detected via ChimeraSlayer and subsequently removed. Chimera check was followed by excluding plant-originated plastid sequences using BLASTn algorithm (Altschul et al., 1990). Remaining sequences were clustered at $97 \%$ similarity using the UCLUST algorithm (Edgar, 2010) and taxonomic assignment of representative sequences were performed using the RDP naive Bayesian rRNA classifier (Wang et al., 2007) based on the reference database Greengenes release 13_5 (De Santis et al., 2006). Read number per sample was normalized to 5578. Rarefaction analysis (species level at 97\%), richness estimates, and diversity indices were calculated; Shannon (1997) and Chaol (Chao and Bunge, 2002) indices were calculated based on the complete linkage clustering data. For OTU-based analysis, only OTUs accounting for at least $1 \%$ of total reads were considered. Classifications of the reads (one representative per OTU) were performed by manual alignment of representative sequences with 16S rRNA reference gene sequences from NCBI database using BLASTn algorithm. Raw pyrosequencing data were deposited at the National Center for Biotechnology Information under the BioProject number PRJNA233435 with the SRA accession numbers SRX652486 (WB-CS), SRX652836 (CS), SRX652838 (SB-CS), SRX652839 (SB-PS), SRX652840 (PS).

\section{ISOLATION AND CHARACTERIZATION OF BACTERIA}

The homogenized suspensions of wild beet rhizosphere replicates were used for dilution and plating on R2A (Roth, Karlsruhe, Germany), and Kings B amended with ampicillin $\left(50 \mu \mathrm{g} \mathrm{ml}^{-1}\right)$, novobiocin $\left(45 \mu \mathrm{g} \mathrm{ml}^{-1}\right)$, and cycloheximide $\left(50 \mu \mathrm{g} \mathrm{ml}^{-1}\right)$. Each dilution was plated in duplicates. Plates were incubated for 5 days at room temperature (RT) and colony forming units (CFU) were counted to calculate the means of colonies $\left(\log _{10} \mathrm{CFU}\right)$ based on fresh weight ( $\mathrm{fw}$ ). To obtain the microbial communities of commercial sugar beet plants (SB-CS, SB-PS), 2 weeks after germination the culturable fraction of the rhizospheres were harvested, suspended, diluted, and plated as described above. If possible, 24 bacterial isolates were selected randomly for each replicate and subsequently cultured on nutrient agar (NA). Due to the limited amount of CS, fewer replicates were available and therefore, a lower number of bacteria were isolated. The isolates were purified and then stored at $-70^{\circ} \mathrm{C}$ in nutrient broth II (NB II) (Sifin, Berlin, Germany) stocks containing $15 \%(\mathrm{v} / \mathrm{v})$ glycerol. Isolates were encoded using a combination of letters and numbers indicating: (1) plant/soil type (WB-wild beet plants grown in coastal drift line soil WB-CS, $\mathrm{VN}$-sugar beet plants cultivated in coastal drift line soil, VSsugar beet plants cultivated in potting soil), (2) replicate (1-4), (3) consecutive number of the isolate per replicate, and (4) origin of the medium (no further indication-bacteria from R2A, Ps-Pseudomonadaceae from Kings B). Bacteria with the highest antagonistic activity and stress tolerance were identified by sequencing partially the $16 \mathrm{~S}$ rRNA gene using the primer pair 27f/1492r (Lane, 1991). Purified fragments were sequenced using LGC Genomics GmbH sequencing service (Berlin, Germany) and identified as described. Sequences obtained were submitted to EMBL Nucleotide Sequence Database under accession numbers KJ024636 to KJ024701. Co-occurrence of 16S rRNA genes from isolates and OTUs obtained by pyrosequencing was determined by aligning corresponding regions using BLASTn algorithm.

\section{SCREENING FOR BACTERIA ANTAGONISTIC TOWARD PLANT PATHOGENS}

The antagonistic potential of randomly selected isolates was assessed by in vitro inhibition of sugar beet-pathogenic fungi Alternaria alternata Nees, Botrytis cinerea Persoon, Rhizoctonia solani Kühn AG2-2IIIB, Sclerotinia sclerotiorum Fuckel, and Verticillium dahliae Klebahn V25 according to Berg et al. (2002). Zones of inhibition were measured 3-7 days after incubation at $25^{\circ} \mathrm{C}$.

\section{SCREENING FOR STRESS TOLERATING BACTERIA}

Overnight cultures grown in $10 \mathrm{ml}$ NBII were used as inoculum $(5 \mu \mathrm{l})$ for all bacterial assays. For desiccation assays, $20 \mu \mathrm{l}$ of culture fluids were dried under sterile conditions. After 3, 6, 9, 16, 21, and 56 days, bacteria were re-suspended with the same volume NBII and dropped on NA. Re-cultivated cells were registered in a positive/negative response. For osmolarity stress, bacteria were cultivated in a 96-well plate filled with $145 \mu \mathrm{l}$ per well modified Luria Bertani (per liter: peptone $3 \mathrm{~g}$, meat extract $5 \mathrm{~g}$ ) with various sodium chloride concentrations (1\% steps, $0-20 \%)$ and incubated at $30^{\circ} \mathrm{C}$ for $48 \mathrm{~h}$ under agitation. In reactive oxygen species stress assays, bacteria were cultivated in NBII amended with different tellurite $\left(1,3,5,7\right.$, and $\left.9 \mathrm{mg} \mathrm{ml}^{-1}\right)$ and $\mathrm{H}_{2} \mathrm{O}_{2}$ $(0.1,0.3,0.5,0.7$, and $0.9 \mathrm{mM})$ concentrations. The assays were performed in 96-well-plates filled with $195 \mu \mathrm{l}$ medium per well and $5 \mu 1$ 1:100 diluted overnight incubated culture. Optical density (OD) was measured for all 96-well plates at $600 \mathrm{~nm}$. Bacterial growth was positively evaluated when $\mathrm{OD}_{600}$ was higher than 0.2 (that is 5-fold higher than the untreated control) after $24 \mathrm{~h}$.

\section{STATISTICS}

Significant differences of $16 \mathrm{~S}$ rRNA gene based fingerprints between all samples were calculated with permutation analysis of pairwise similarities using permtest package for $\mathrm{R}$ statistics (The $\mathrm{R}$ Foundation for Statistical Computing Version 2.1.1) (Kropf et al., 2004). Other significant differences were calculated using ANOVA with post-hoc test Scheffé in SPSS-PASW Statistics v.18. 


\section{RESULTS}

\section{MOLECULAR FINGERPRINTS OF 16S rRNA GENES OF THE BACTERIAL COMMUNITIES}

Molecular fingerprints were performed by SSCP analysis of $16 \mathrm{~S}$ rRNA genes amplified from DNA obtained from all samples to gain first insight into the bacterial communities. Bacterial fingerprints of potting soil samples (SB-PS and PS) comprised fewer but more dominant bands compared to the SSCP profiles from WB-CS, SB-CS, and CS, where a higher number of SSCP bands were detected (Figure S1). According to cluster analyses, bacterial communities from SB-CS and CS significantly differed by $78 \%$ from SB-PS and PS $(P \leq 0.001)$, which clearly indicated the high impact of soil type and the composition of bacterial fingerprints. In addition, the rhizosphere effect was highly pronounced: SB-CS and SB-PS were significantly different from their respective bulk soils CS and PS by $72 \%(P \leq 0.029)$ and $52 \%$ $(P \leq 0.028)$, respectively, (Figure 1). Differences between both investigated plant genotypes were also identified: the WB-CS rhizosphere was separated from all others and showed only $16 \%$ similarity with the SB-CS rhizosphere. Noticeably, due to different life cycles not only the genotype but also the plant developmental stage were different and could account for observed effects.

\section{PYROSEQUENCING-BASED 16S rRNA PROFILING OF THE BACTERIAL COMMUNITIES}

A pyrosequencing-based analysis of partial 16S rRNA gene sequences was employed to survey the diversity and composition of the bacterial rhizosphere communities in WB-CS, SB-CS and SB-PS, and the respective bulk soils CS and PS. In all samples, we recovered between 5578 and 9567 quality sequences with read lengths ranging from 430 to $450 \mathrm{bp}$. Prior to further analysis, read numbers were normalized to 5578 for each sample. To calculate rarefaction curves and to perform taxonomic assignments, reads were clustered in operational taxonomic units (OTUs) at sequence divergences of $3 \%$ (species level). The rarefaction curves of the bacterial communities of WB-CS, SB-CS, SB-PS, and their respective bulk soils $\mathrm{CS}$ and $\mathrm{PS}$ are shown in Figure S2. At a dissimilarity level of $3 \%$, the curves of WB-CS and PS samples generally showed low slopes, but did not reach saturation. Accordingly, the number of observed OTUs covers only 31.4 and $34.5 \%$ of the estimated taxonomic richness by the Chaol richness estimator (Table 1). That indicates evenly contributing species and a low number of very common or very rare species. The computed Shannon indices of diversity $\left(\mathrm{H}^{\prime}\right)$ were much higher for the wild beet plants grown in coastal drift line soil (WB-CS) and the sugar beets grown therein SB-CS, and CS $(8.7,8.1,8.2)$ than for SB-PS and PS $(6.0,4.3)$.

Altogether, $98.8 \%$ of the OTUs (total number: 5163) were affiliated to 10 different phyla representing at least $1 \%$ of reads (Figure 2): Actinobacteria and Proteobacteria were found in all samples. Only in WB-CS, SB-CS, and CS Acidobacteria (8.7, 13.0, 17.1\%), Chloroflexi (4.3, 7.0, 6.0\%), Gemmatimonadetes (1.6, 4.7, 3.7\%), and Planctomycetes $(26.9,39.3,36.3 \%)$ were found. Bacteroidetes were found exclusively in rhizospheres of WB-CS (2.7\%) and SB-PS (14.1\%). Low percentages of Fibrobacteres were found exclusively in the rhizosphere of SB-CS

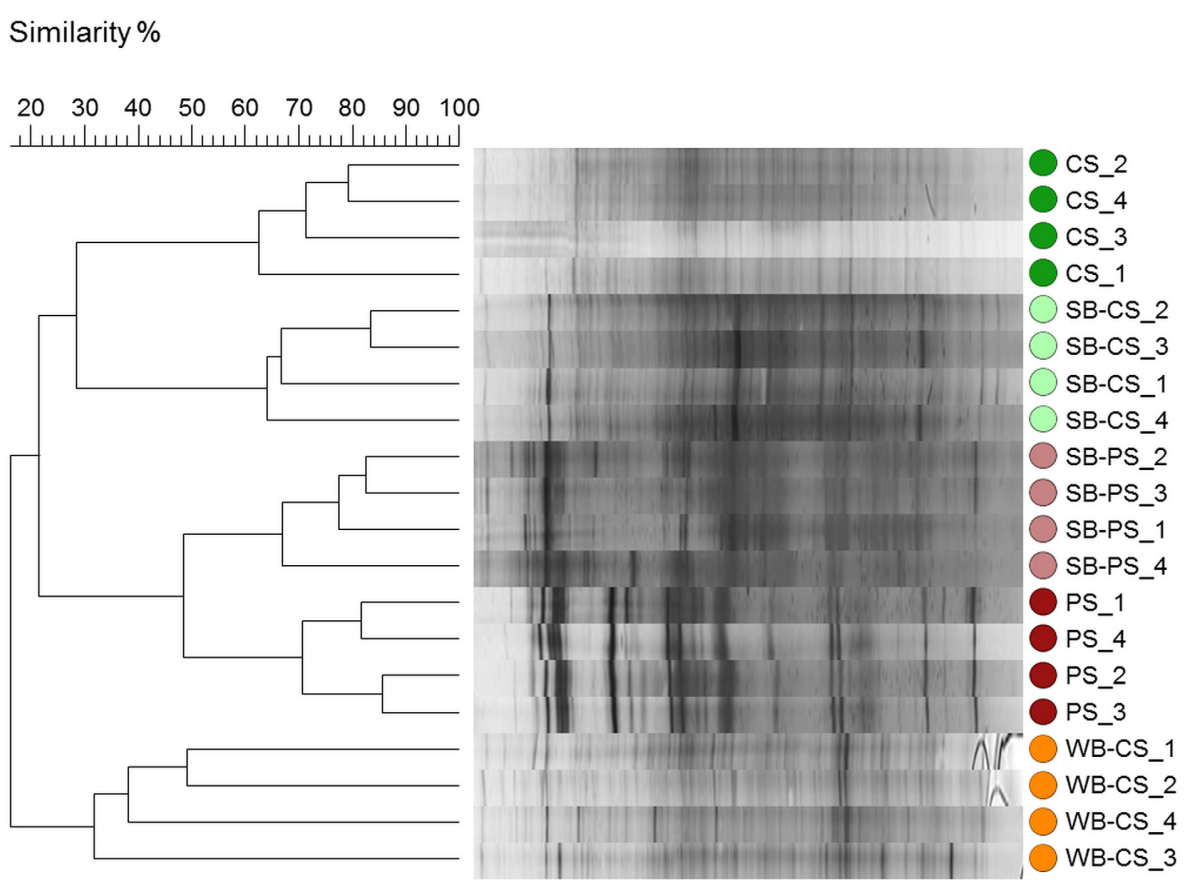

FIGURE 1 | Dendrogram of 16S rRNA gene-based SSCP profiles of bacterial communities in association with wild beet (WB-CS) and sugar beet rhizosphere grown in coastal drift line (SB-CS) and potting soil (SB-PS) and their respective bulk soils (CS, PS) with four repetitions per sample. Following settings were used: dendrogram type: unweighted pair group method with arithmetic mean (UPGMA); similarity coefficient: curve based, Pearson correlation; optimization: $4 \%$, position tolerance: $1 \%$. 
$(1.0 \%)$ and Verrucomicrobia in the rhizosphere of WB-CS $(1.7 \%)$.

\section{SOIL TYPE- AND PLANT GENOTYPE-SPECIFIC OTUs}

A more detailed analysis of the dominant soil and plant genotypespecific OTUs was performed on the base of a manual taxonomic assignment by BLASTn alignment using NCBIs 16S rRNA gene reference database. In total, 48 OTUs were obtained when a cut-off level of $1 \%$ was applied (Table 2). The dominant genus within the phylum Proteobacteria was Pseudomonas comprising four species (OTU1726, 2094, 2281, 4102) with the relative abundance of $18.8 \%$ detected in the SB-PS rhizosphere, $1.8 \%$ WB-CS rhizosphere, $0.2 \%$ in the SB-CS rhizosphere, and 16.9 and $0.1 \%$ in PS and CS, respectively. The

Table 1 | Species richness (normalized at 5578 sequences per sample) estimates obtained at $3 \%$ genetic dissimilarity from 454 pyrosequencing-derived sequences of DNA extracted from SB-CS-Sugar beet plants cultivated in coastal drift line soil, SB-PS-Sugar beet plants cultivated in potting soil, WB-CS-Wild beet plants grown in coastal drift line soil, CS-Coastal drift line soil, PS-Potting bulk soil.

\begin{tabular}{llcccc}
\hline $\begin{array}{l}\text { Sample Sample } \\
\text { ID }\end{array}$ & $\begin{array}{c}\text { Shannon } \\
\text { index }^{\mathbf{a}} \text { (H') }\end{array}$ & $\begin{array}{c}\text { Rarefaction }^{\mathbf{b}} \\
\text { (no. of OTUs) }\end{array}$ & $\begin{array}{c}\text { Chao1 }^{\mathbf{c}} \\
\text { (no. of OTUs) }\end{array}$ & $\begin{array}{c}\text { Coverage } \\
\text { (\%) }\end{array}$ \\
\hline MID1 & WB-CS & 8.7 & 1369.9 & 4356.9 & 40.6 \\
MID2 & CS & 8.2 & 1156.1 & 3153.2 & 36.7 \\
MID3 & SB-CS & 8.1 & 1190.7 & 2930.2 & 36.7 \\
MID4 & SB-PS & 6.0 & 361.5 & 986.2 & 34.5 \\
MID5 & PS & 4.3 & 121.3 & 351.1 & 31.4 \\
\hline
\end{tabular}

${ }^{a}$ higher number indicates more diversity; ${ }^{b}$ results from the rarefaction analyses; ${ }^{c}$ non-parametric richness estimator based on the distribution of singletons and doubletons. second major genus assigned to Stenotrophomonas comprised only one OTU (3731), and was detected in the SB-PS (1.8\%) and WB-CS (0.4\%) rhizosphere, and in PS (21.1\%). Most of the Firmicutes sequences belonged to the genus Paenibacillus comprising three species (OTU1033, 2251, 3065) in SB-PS $(0.2 \%)$ and PS (8.3\%), followed by Bacillus (OTU379) in the SB-PS $(0.2 \%)$ and WB-CS rhizosphere $(0.1 \%)$, and in PS $(6.7 \%)$. Blastopirellula, the main genus within the phylum Planctomycetes, occurred in approximately equal abundances in the SB-CS $(4.9 \%)$ and WB-CS (4.0\%) rhizosphere, and in CS (5.2\%). The majority of Bacteroidetes reads belonged to Flavobacterium (OTU254, 3902) and Pedobacter (OTU172, 3215) detected in the SB-PS and WB-CS rhizosphere. Within the Actinobacteria, Thermoleophilum occurred as the only genus (OTU745) in the SB-CS (3.1\%) and WB-CS rhizosphere (0.6\%), and CS $(2.5 \%)$. Within the Acidobacteria the OTU945 assigned to Candidatus Solibacter occurred with $0.7 \%$ in SB-CS, $0.2 \%$ WB-CS, and $1.3 \%$ in CS.

Comparing wild beet and sugar beet cultivated in CS, 20 out of 38 dominant OTUs $(41.7 \%)$ were detected in both rhizospheres, whereas 18 OTUs (37.5\%) accounting for $2.3 \%$ of total reads occurred exclusively in WB-CS, i.e., OTU172, 254, $1122,1155,2094,2281,2797,3190,3215,3262,3731,3889$, 3902, 3915, 3972, 4395, 5140, 5143 (Table 2). The WB-CSspecific OTU with the highest percentage of reads $(0.5 \%)$ was OTU2094 assigned to Pseudomonas grimontii. Remarkably, none of the OTUs was found to be specific for SB-CS. In the soil type comparison of sugar beet plants cultivated in CS and PS, 12 specific OTUs (25.1\% of total reads) were found in SB-CS and 25 in SB-PS (33.7\%). In SB-CS, the most dominant and specific OTU (5.6\%) was assigned to Angiococcus disciformis (OTU1264) and in SB-PS to Enterobacter sp. with $6.1 \%$ (OTU3915). Altogether, a high impact of soil type and also of plant genotype on the rhizosphere communities was observed.

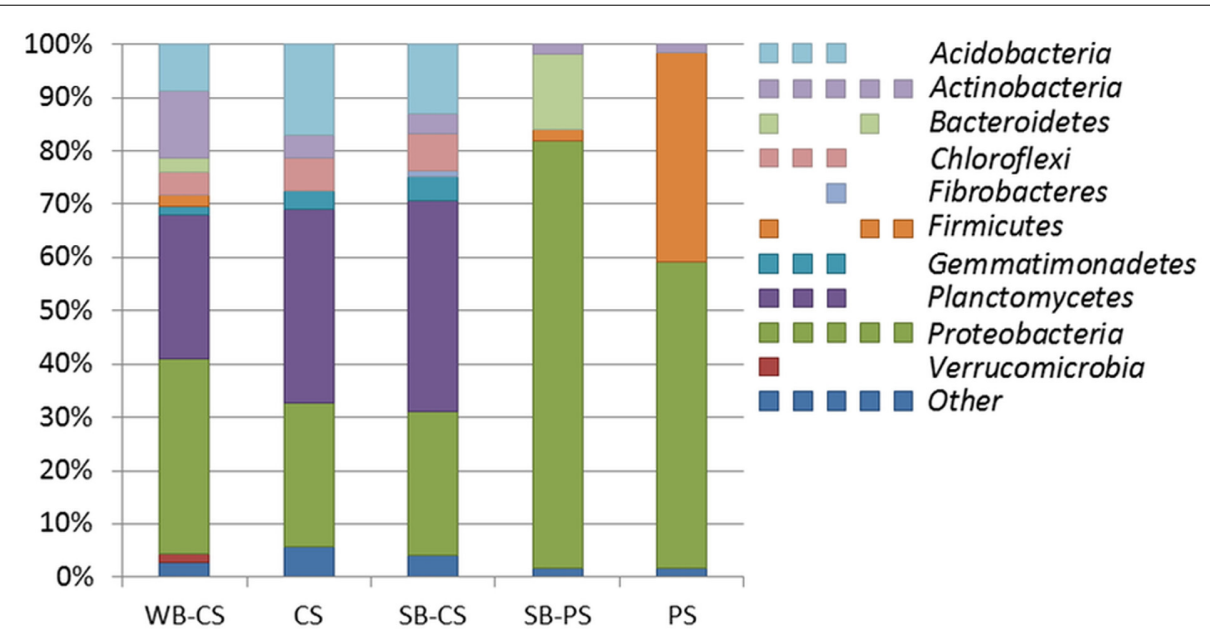

FIGURE 2 | The structure of bacterial communities at phylum level of wild beet rhizosphere (WB-CS), coastal drift line bulk soil (CS), sugar beet plants cultivated in coastal drift line soil (SB-CS), sugar beet plants cultivated in potting soil (SB-PS), and potting bulk soil (PS). Relative composition of

major phyla ( $>1 \%$ of total reads) was determined by 454 amplicon pyrosequencing of $16 \mathrm{~S}$ rRNA extracted from all samples. Multi-colored charts at the legend are shown for each phylum and sample correspondingly. Phyla to which $<1 \%$ of reads were assigned were summarized as "other." 
Table 2 | Taxonomic classification and relative abundance of dominant OTUs (cut-off level: 1\%) from rhizosphere and soil samples.

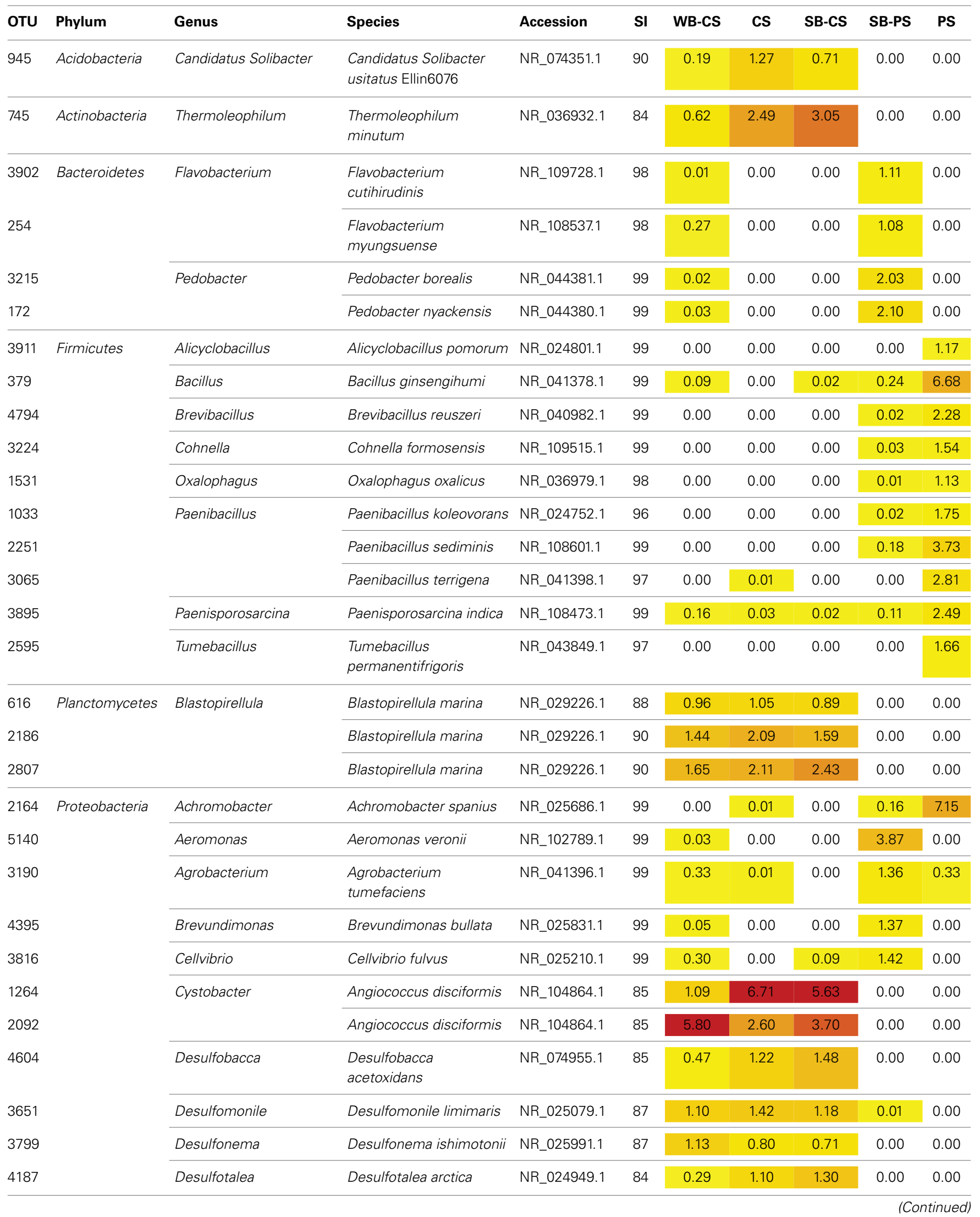


Table 2 | Continued

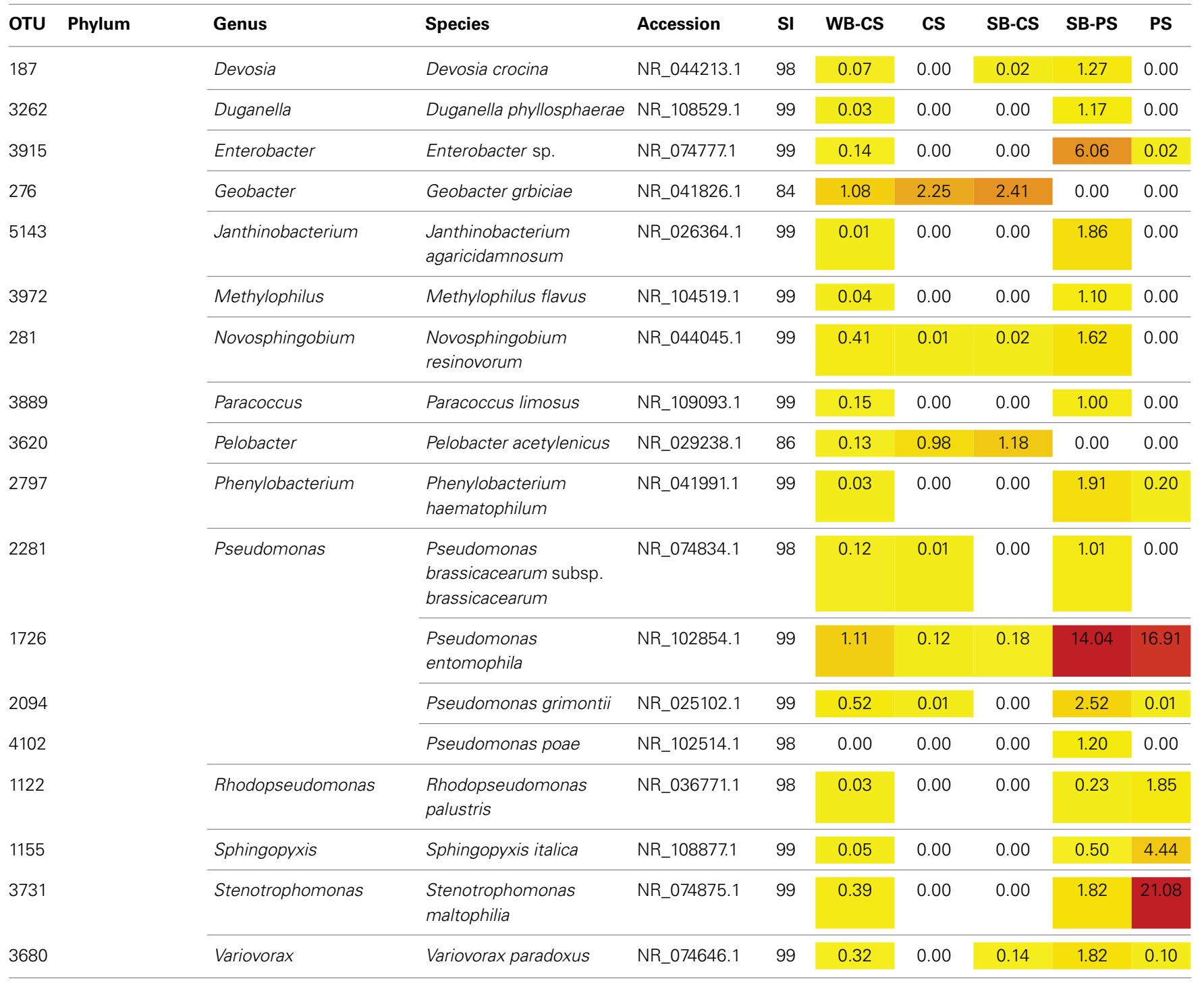

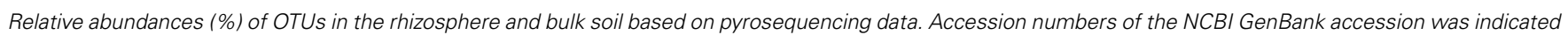

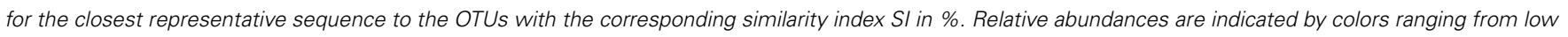
abundances (yellow) raising to a high abundance (red). Non-detected OTUs in respective samples are white colored.

\section{COMPARATIVE ANALYSES OF RHIZOSPHERE AND BULK SOIL RESPONDERS}

Taxonomic comparisons were done at genus level for representative sequences of all OTUs obtained by clustering at $97 \%$ similarity. Classification was performed using the RDP naïve Bayesian rRNA classifier and Greengenes 16S rRNA database. Overall, $37.4 \%$ of the sequences could be assigned to 70 genera with a confidence score of $\geq 80 \%$ (Table S2). By comparing CS and WB-CS, 44 taxa assigned to eight phyla were detected (including Other). In general, 31 taxa responded positively in the rhizosphere with increased ratio higher than 2, where the highest ratio was found for Novosphingobium sp. (74.4) followed by Pseudomonas sp. (50.8). Comparing CS and SB-CS, only six taxa (ratio $>2$ ) were positive rhizosphere responders with the highest ratio found for Cellvibrio sp. (6.1) followed by Aquimonas sp.
(4.3); whereas 32 taxa were not detected at all in CS. By comparing PS and SB-PS seven taxa (ratio $>2$ ) were detected with the highest ratio of 116.0 found in the rhizosphere and assigned to Sphingomonas sp. followed by Pseudomonas sp. (90.6). Fiftytwo taxa were not detected in PS. For wild beet plants in CS and sugar beet plants cultivated in CS and PS, the rhizosphere effect could be confirmed. In general, a stronger rhizosphere effect was observed for sugar beet plants in potting soil compared to plants cultivated in coastal drift line soil.

\section{BACTERIAL ANTAGONISTS AND THEIR STRESS RESPONSE}

In total, 576 bacteria were isolated; 192 isolates were selected from WB-CS, 144 from SB-CS, and 312 from SB-PS rhizospheres. The lower number of isolates from WB-CS and SB-CS resulted from the limited amount of sample material. All bacteria were tested in 
dual culture assays for their in vitro antagonistic activity against various sugar beet phytopathogens. In total, 357 bacteria were positive against at least one of the phytopathogens. The highest proportion of antagonistic bacteria originated from Kings B agar compared to R2A (Table 3 ).

The highest percentage of antagonists were found for bacteria isolated from SB-PS (R2A $15.0 \pm 9.7$, Kings B $57.5 \pm$ 11.6) against Botrytis cinerea independently from the selection medium. Within isolates from R2A, a higher percentage of active bacteria were found from SB-CS compared to WB-CS except for Sclerotinia sclerotiorum. Similarly, for bacteria isolated from Kings $\mathrm{B}$, a higher percentage of active bacteria were isolated from SBCS compared to WB-CS against A. alternata, S. sclerotiorum, and $V$. dahliae, except for $B$. cinerea and $R$. solani. When cultivated in different soil types, isolates from SB-PS (Kings B) showed a higher antagonistic percentage against $B$. cinerea and $R$. solani and less activity against $A$. alternata compared to SB-CS.

All positively evaluated bacterial isolates (357) were further tested for their ability to tolerate stress including desiccation, salt, and reactive oxygen species caused by hydrogen peroxide and tellurite (Figure 3). In desiccation assays, the survival of the cells over several days was tested. In general, slightly more isolates obtained from the Kings B medium could be re-cultivated after 3 , 6, and 16 days when compared to R2A. After 56 days, most of the isolates were not able to be re-cultivated after desiccation (Figure 3A). In salt ( $\mathrm{NaCl})$ stress assays, a high percentage of isolates from WB-CS and sugar beet plants cultivated in the same soil (SB-CS) were able to grow in the presence of up to $6 \%$ salt. The majority of bacteria from all samples could deal with a maximal salt concentration of $6 \%$; with the exception of SB-PS, where most of the isolates were unable to grow above $2 \% \mathrm{NaCl}$ (Figure 3B). In the presence of reactive oxygen species (ROS) induced by hydrogen peroxide and tellurite, 68.0 and $28.2 \%$, respectively, of the antagonists were able to cope with the lowest concentration, and 1.1 and $4.5 \%$, respectively, with the highest concentration. The highest percentage of isolates able to deal with high ROS concentrations caused by hydrogen peroxide were determined for isolates from WB-CS (0.1 mM: $91.7 \%$; $0.3 \mathrm{mM}$ : $53.3 \%$; $0.5 \mathrm{mM}$ : $16.7 \%$ ) selected on Kings B (Figure 3C). The maximum concentration of hydrogen peroxide at which isolates were able to grow was $0.7 \mathrm{mM}$. None of the isolates from SB-CS and from Kings B were able to grow in the presence of $\mathrm{H}_{2} \mathrm{O}_{2}$. Among all samples, only a few isolates were able to tolerate high ROS concentrations from tellurite. These isolates were obtained from SB-CS. The maximum concentration of tellurite at which isolates were able to grow was $9 \mathrm{mg} \mathrm{ml}^{-1}$ (Figure 3D).

Bacterial isolates with the highest antagonistic activity and stress tolerance were identified (Table 4). From all samples, isolates of Pseudomonas and Stenotrophomonas species were identified. Isolates from the sugar beet rhizospheres (SBCS, SB-PS) were mainly identified as Staphylococcus and Stenotrophomonas species. In contrast, from WB rhizospheres more diverse bacterial species were isolated, i.e., Curtobacterium sp., Erwinia sp., Microbacterium sp., Micrococcus sp., Streptomyces sp., Sphingobacterium sp., Agrobacterium sp., Luteimonas sp., Pseudomonas sp., Rheinheimera sp., and Stenotrophomonas sp. Based on their 16S rRNA gene similarity, the abundance of bacterial isolates in the amplicon libraries was calculated. In all samples, 16S rRNA sequences were detected of species to which the active isolates were affiliated. Their relative abundances ranged from 0.01 to $2.94 \%$ with the highest abundances of Pseudomonas and Stenotrophomonas.

\section{DISCUSSION}

In this study, we found differences within the microbiome composition of the sugar beet rhizosphere and its wild ancestor. At phylum level, the rhizosphere microbiome of wild beet and domesticated sugar beet plants (WB-CS, SB-CS) resembled each other independently from the climate and plant development, whereas, at a higher taxonomic resolution plant genotype-specific patterns were identified. This plant genotype-specific effect was confirmed for functional traits. The wild beet rhizosphere (WBCS) was colonized by a low number of bacteria with antagonistic activity against pathogens but their antagonists showed a high potential to cope with abiotic stresses. Conversely, the sugar beet cultivar was able to enrich a high antagonistic potential from both soil types but harbored less antagonists with high stress resistance. In addition, an impact of both soil types (CS, PS) on the bacterial composition was found. However, the differences in structure and function of the microbiomes of ancient and modern beets underline the relationship between the plant genotypes and their associated bacteria and confirmed our hypotheses.

Table 3 | Antagonistic potential toward various plant pathogens.

\begin{tabular}{|c|c|c|c|c|c|c|c|}
\hline Origin & Cultivation medium & No. of isolates ${ }^{a}$ & A. a. $(\%)$ & B. c. $(\%)$ & R. s. $(\%)$ & S. s. $(\%)$ & V. d. $(\%)$ \\
\hline WB-CS & $\mathrm{R} 2 \mathrm{~A}$ & 96 & $7.3 \pm 10.2 \mathrm{a}$ & $4.2 \pm 7.1 \mathrm{a}$ & $0.0 \pm 0.0 \mathrm{a}$ & $2.1 \pm 3.5 \mathrm{a}$ & $2.1 \pm 3.5 \mathrm{a}$ \\
\hline SB-CS & $\mathrm{R} 2 \mathrm{~A}$ & 72 & $12.5 \pm 3.3 \mathrm{a}$ & $10.4 \pm 8.9 a$ & $2.1 \pm 3.5 \mathrm{a}$ & $2.1 \pm 3.5 a$ & $12.5 \pm 16.8 b$ \\
\hline SB-PS & $\mathrm{R} 2 \mathrm{~A}$ & 120 & $1.7 \pm 2.1 \mathrm{a}$ & $15.0 \pm 9.7 \mathrm{a}$ & $0.8 \pm 1.5 \mathrm{a}$ & $1.7 \pm 2.1 \mathrm{a}$ & n.d. \\
\hline WB-CS & Kings B & 96 & $17.7 \pm 15.6 \mathrm{a}$ & $45.8 \pm 20.2 \mathrm{ab}$ & $10.4 \pm 8.9 \mathrm{a}$ & $1.0 \pm 1.8 \mathrm{a}$ & $4.2 \pm 2.9 \mathrm{a}$ \\
\hline SB-CS & Kings B & 72 & $20.8 \pm 8.2 \mathrm{a}$ & $27.1 \pm 3.5 \mathrm{a}$ & $4.2 \pm 7.1 \mathrm{a}$ & $16.7 \pm 11.5 b$ & $20.8 \pm 7.1 b$ \\
\hline SB-PS & Kings B & 120 & $10.1 \pm 5.5 a$ & $57.5 \pm 11.6 b$ & $4.6 \pm 2.5 \mathrm{a}$ & n.d. & n.d. \\
\hline
\end{tabular}

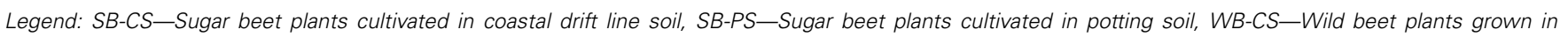

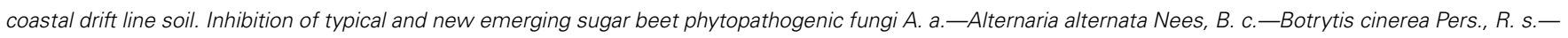

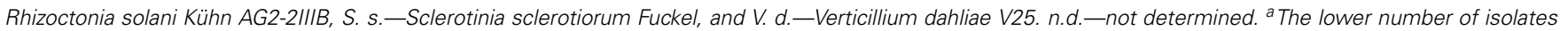
from WB-CS and SB-CS resulted from the limited amount of sample material. 


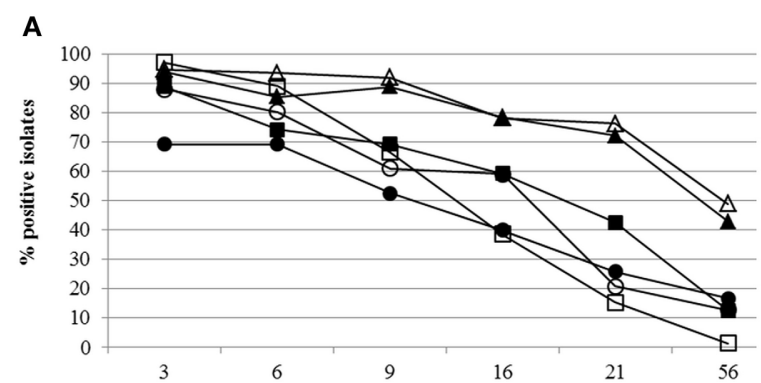

C

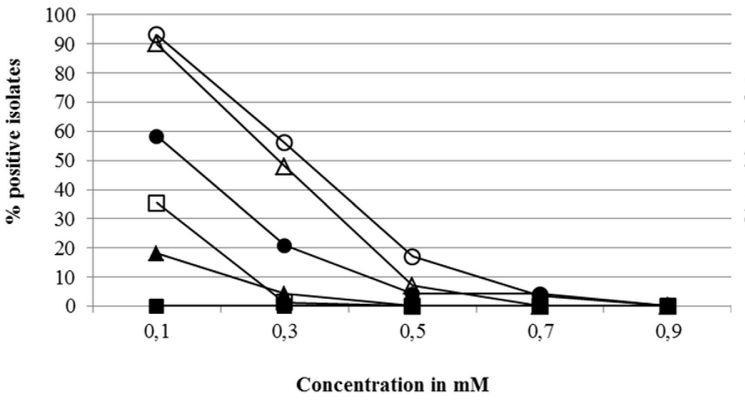

FIGURE 3 | Stress tolerance assays. Bacterial isolates able to be re-cultivated after desiccation (A), grown in presence of different sodium chloride concentrations (B), and cultivated in presence of reactive oxygen species caused by hydrogen peroxide (C) and tellurite (D). In total, 357 antagonistic bacteria, previously selected from R2A or Kings B medium, were

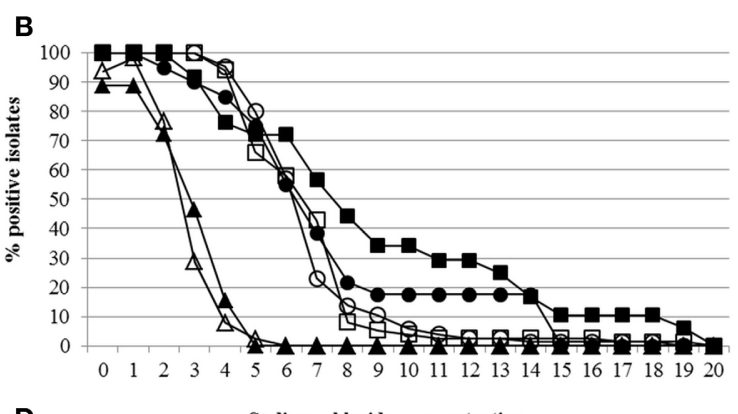

D

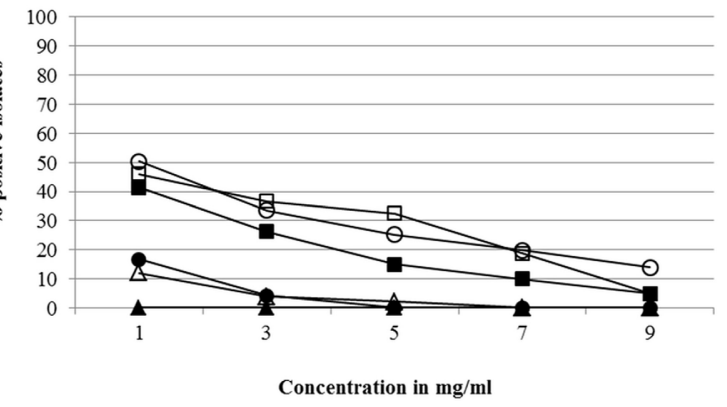

tested. Legend: bacteria isolated from R2A—closed symbols, and from Kings B-open symbols; wild beet rhizosphere (WB-CS)—circle, rhizosphere of sugar beet plants cultivated in coastal drift line soil (SB-CS)—square, rhizosphere of sugar beet plants cultivated in potting soil (SB-PS) - triangle. Further statistics were indicated in Tables S3A-D.
The composition of the microbiome of both plant genotypes, when grown in CS, was comparable at phylum level. However, resolved at OTU level, based on results from molecular fingerprint analysis and amplicon pyrosequencing of 16S rRNA genes, plant genotype-specific OTUs were detected. The wild beet (WB-CS) showed the highest number of unique bands in bacterial fingerprints but the bacterial communities in the rhizosphere of sugar beet (SB-CS) and in bulk soil (CS) were similar to each other. Based on amplicon libraries, the WB-CS rhizosphere consisted of 18 unique out of 38 detected OTUs including Flavobacterium, Pedobacter, and Pseudomonas spp. In contrast, no specific OTUs could be identified for SB-CS. The low rhizosphere effect in SB-CS might be a result of the shorter growth period in addition to the different climate. The majority of the dominant OTUs (20) was shared by SB-CS and WB-CS and included genera of the phyla Actinobacteria (Thermoleophilum), Proteobacteria (Cystobacter, Desulfomonile), and Planctomycetes (Blastopirellula). In all rhizospheres (CS), the myxobacterium Angiococcus disciformis was found in highest relative abundances. The more diverse spectrum of OTUs associated with wild beet plants compared to SB-CS was confirmed by the elevated Shannon index, which was 8.7 for WB-CS and 8.1 for SB-CS. The impact of the plant genotype on the associated microbiota, which was clearly shown in our study, was dependent on the applied method and their taxonomic resolution. This genotype-specific impact was also shown or other crops such as maize (Peiffer et al., 2013), potato (Weinert et al., 2009, 2011), and rice (Engelhard et al., 2000; Hardoim et al., 2011).
In addition to the plant genotype-specific community structures, we found differences in in vitro functions of the isolates as well. The proportion of strains with antagonistic in vitro activity against phytopathogens was lower in the rhizosphere WB$\mathrm{CS}$ in comparison to the domesticated sugar beet SB-CS and SB-PS. The lower antagonistic activity of wild beet-associated bacteria can be traced back to the fact that pathogen pressure barely exists in coastal drift-line soil as it is influenced by seawater spray, tidal flow, and storms (Biancardi et al., 2012). In contrast, modern sugar beets are threatened by many diseases including fungal pathogens which were involved in this study (Khan, 2013). Under agricultural conditions, the pathogen pressure is often much higher than in natural habitats; one reason for this can be the naturally occurring biodiversity which protects ecosystems from spread of diseases (Latz et al., 2012). B. maritima grows under extreme saltwater conditions, and can tolerate both high salt concentrations in soil and severe drought (Shaw et al., 2002). Wild beet-associated bacterial isolates showed a higher extend of stress tolerance than isolates of domesticated sugar beet plants with in vitro antagonistic activity. These isolates were identified mainly as Pseudomonas and Stenotrophomonas species; members of both are well-known for their ability to cope with biotic and abiotic stress (Alavi et al., 2013; Zachow et al., 2013). Within the amplicon libraries their relative abundances was lower than $1 \%$. However, the protective functions can be fulfilled by a minor fraction, which may contribute to important ecosystem functions (Pester et al., 2010). 


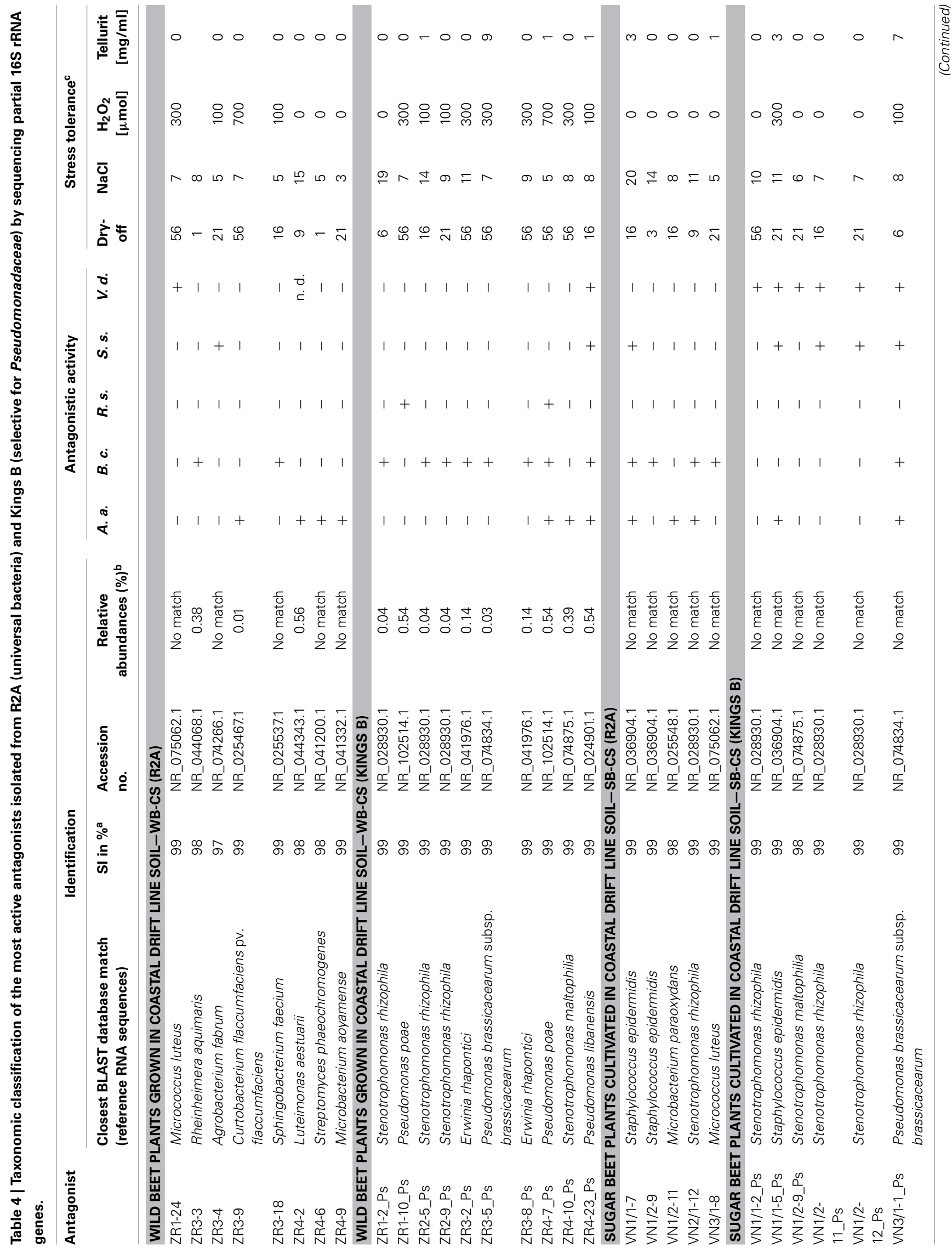




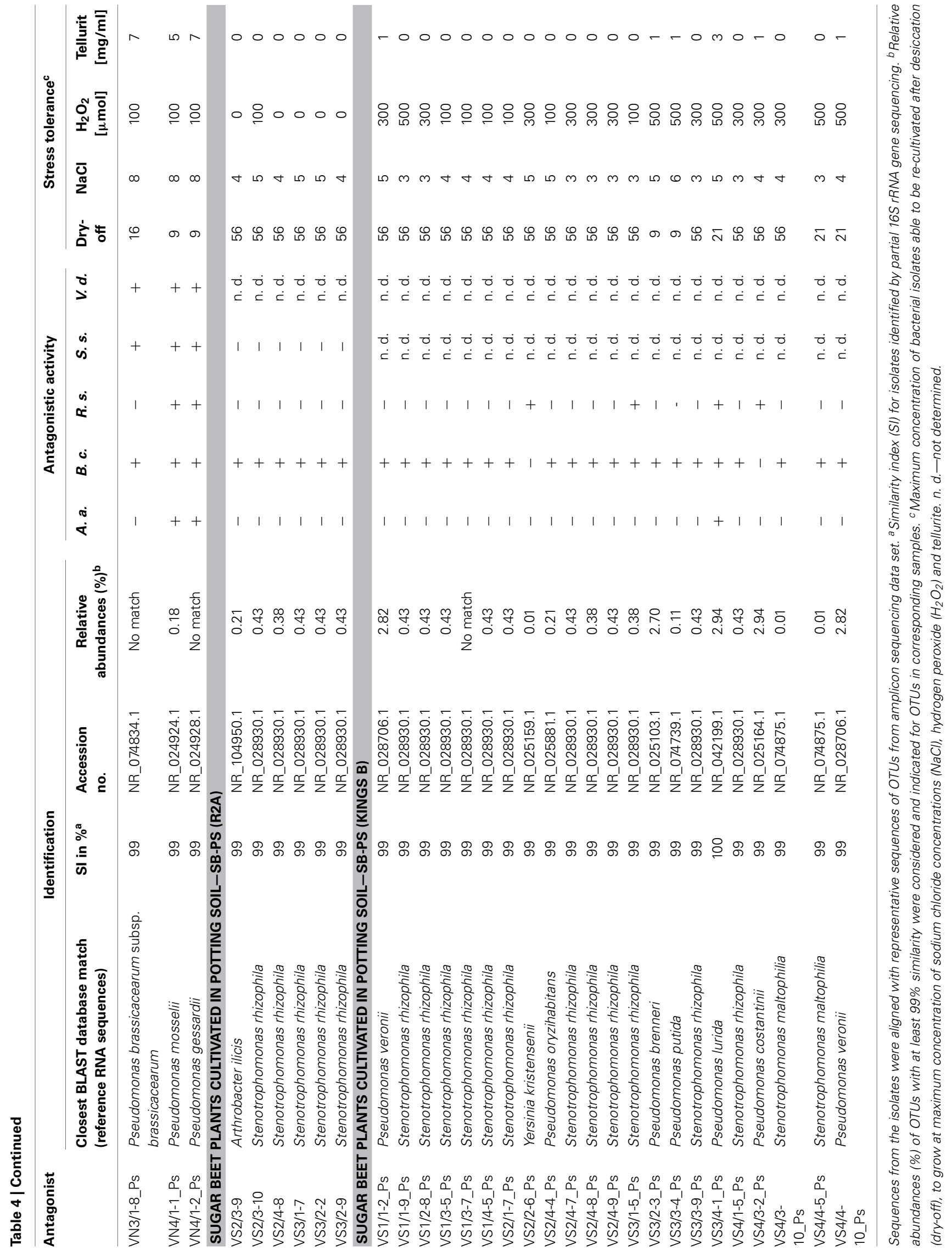


The community composition of both sugar beet genotypes showed clear soil type-specific effects. In bacterial fingerprints, SB-CS showed only $36 \%$ similarity to that of SB-PS. Based on the pyrosequencing approach, the phyla Actinobacteria and Planctomycetes were pin-pointed as determinants for these differences. These taxa were found exclusively in WB-CS and SB-CS. Planctomycetes are known as soil oligotrophes and were enriched in the bulk soil compared to the maize rhizosphere (Peiffer et al., 2013). Bacteroidetes and Proteobacteria were important members of the rhizosphere community. At OTU level the most dominant OTUs belong to the genus Pseudomonas. Sugar beets were previously reported as highly colonized by Pseudomonas species using a broad variety of techniques (Lambert et al., 1990; Thrane et al., 2000; Zachow et al., 2008; Mendes et al., 2011). In the current study, Pseudomonas species were detected within all bacterial communities using fingerprint and pyrosequencing analysis. In bacterial fingerprints, Pseudomonas species were mainly detected in samples grown in PS and were less dominant in the rhizosphere samples cultivated CS. Interestingly, pseudomonads appears to have a minor relevance for the investigated Beta genotypes grown or cultivated in their natural habitat.

In this study, we compared the microbiome of both ancestral and domesticated beet rhizospheres and linked functions to particular isolates within the bacterial community. These results support the suggestion by Wissuwa et al. (2009) to apply the knowledge of plant genotype-specific traits of associated microorganisms for breeding strategies. Moreover, wild types of crops as well as soil from their original distribution area are important sources for isolates with antagonistic activity against plant pathogens or with stress protecting activity for their hosts.

\section{AUTHOR CONTRIBUTIONS}

Christin Zachow, Henry Müller, Gabriele Berg conceived and guided the research, and wrote the manuscript. Ralf Tilcher provided experimental suggestions. Christin Zachow, Henry Müller performed the laboratory experiments and bioinformatoric analyses.

\section{ACKNOWLEDGMENTS}

The authors thank Barbara Fetz, Monika Schneider-Trampitsch, and Melanie Marek (Graz) for valuable technical assistance. This work has been supported by a grant to Gabriele Berg from the Federal Ministry of Economy, Family and Youth (BMWFJ), the Federal Ministry of Traffic, Innovation and Technology (bmvit), the Styrian Business Promotion Agency SFG, the Standortagentur Tirol and ZIT - Technology Agency of the City of Vienna through the COMET-Funding Program managed by the Austrian Research Promotion Agency FFG.

\section{SUPPLEMENTARY MATERIAL}

The Supplementary Material for this article can be found online at: http://www.frontiersin.org/journal/10.3389/fmicb.2014. 00415/abstract

\section{REFERENCES}

Akhalkatsi, M., Ekhvaia, J., and Asanidze, Z. (2012). "Diversity and genetic erosion of ancient crops and wild relatives of agricultural cultivars for food: implications for nature conservation in Georgia
(Caucasus)," in Perspectives on Nature Conservation - Patterns, Pressures and Prospects, ed J. Tiefenbacher (Rijeka: InTech), 51-92. Available online at: http://www.intechopen.com/books/perspectives-on-nature-conservationpatterns-pressures-and-prospects/diversity-and-genetic-erosion-of-ancient-cro ps-and-wild-relatives-of-agricultural-cultivars-for-food

Alavi, P., Starcher, M. R., Zachow, C., Müller, H., and Berg, G. (2013). Rootmicrobe systems: the effect and mode of interaction of Stress Protecting Agent (SPA) Stenotrophomonas rhizophila DSM14405 ${ }^{\mathrm{T}}$. Front. Plant Sci. 4:141. doi: 10.3389/fpls.2013.00141

Altschul, S. F., Gish, W., Miller, W., Myers, E. W., and Lipman, D. J. (1990). Basic local alignment search tool. J. Mol. Biol. 215, 403-410. doi: 10.1016/S00222836(05)80360-2

Berendsen, R. L., Pieterse, C. M., and Bakker, P. A. (2012). The rhizosphere microbiome and plant health. Trends Plant Sci. 17, 478-486. doi: 10.1016/j.tplants. 2012.04.001

Berg, G., Roskot, N., Steidle, A., Eberl, L., Zock, A., and Smalla, K. (2002). Plantdependent genotypic and phenotypic diversity of antagonistic rhizobacteria isolated from different Verticillium host plants. Appl. Environ. Microbiol. 68, 3328-3338. doi: 10.1128/AEM.68.7.3328-3338.2002

Berg, G., and Smalla, K. (2009). Plant species and soil type cooperatively shape the structure and function of microbial communities in the rhizosphere. FEMS Microbiol. Ecol. 68, 1-13. doi: 10.1111/j.1574-6941.2009.00654.x

Berg, G., Zachow, C., Müller, H., Philipps, J., and Tilcher, R. (2013). Nextgeneration bio-products sowing the seeds of success for sustainable agriculture. Agronomy 3, 648-656. doi: 10.3390/agronomy3040648

Biancardi, E., Panella, L. W., and Lewellen, R. T. (2012). Beta Maritima: The Origin of Beets. New York, NY: Springer.

Bulgarelli, D., Rott, M., Schlaeppi, K., van Themaat, E. V. L., Ahmadinejad, N., Assenza, F., et al. (2012). Revealing structure and assembly cues for Arabidopsis root-inhabiting bacterial microbiota. Nature 488, 91-95. doi: 10.1038/nature 11336

Caporaso, J. G., Kuczynski, J., Stombaugh, J., Bittinger, K., Bushman, F. D., Costello, E. K., et al. (2010). QIIME allows analysis of high-throughput community sequencing data. Nat. Methods 7, 335-336. doi: 10.1038/nmeth.f.303

Chao, A., and Bunge, J. (2002). Estimating the number of species in a stochastic abundance model. Biometrics 58, 531-539. doi: 10.1111/j.0006341X.2002.00531.x

Chaparro, J. M., Badri, D. V., Bakker, M. G., Sugiyama, A., Manter, D. K., and Vivanco, J. M. (2013). Root exudation of phytochemicals in Arabidopsis follows specific patterns that are developmentally programmed and correlate with soil microbial functions. PLOS ONE 8:e55731. doi: 10.1371/journal.pone.0055731

Dent, K. C., Stephen, J. R., and Finch-Savage, W. E. (2004). Molecular profiling of microbial communities associated with seeds of Beta vulgaris subsp. vulgaris (sugar beet). J. Microbiol. Methods 56, 7-26. doi: 10.1016/j.mimet.2003. 09.001

De Santis, T. Z., Hugenholtz, P., Larsen, N., Rojas, M., Brodie, E. L., Keller, K., et al. (2006). Greengenes, a chimera checked 16S rRNA gene database and workbench compatible with ARB. Appl. Environ. Microbiol. 72, 5069-5072. doi: 10.1128/AEM.03006-05

Dodić, S., Popov, S., Dodić, J., Ranković, J., Zavargo, Z., and Jevtić Muèibabić, R. (2009). Bioethanol production from thick juice as intermediate of sugar beet processing. Biomass Bioenergy 33, 822-827. doi: 10.1016/j.biombioe.2009. 01.002

Dohm, J. C., Minoche, A. E., Holtgräwe, D., Capella-Gutiérrez, S., Zakrzewski, F., Tafer, H., et al. (2014). The genome of the recently domesticated crop plant sugar beet (Beta vulgaris). Nature 505, 546-549. doi: 10.1038/nature12817

Edgar, R. C. (2010). Search and clustering orders of magnitude faster than BLAST. Bioinformatics 26, 2460-2461. doi: 10.1093/bioinformatics/btq461

Engelhard, M., Hurek, T., and Reinhold-Hurek, B. (2000). Preferential occurrence of diazotrophic endophytes, Azoarcus spp., in wild rice species and land races of Oryza sativa in comparison with modern races. Environ. Microbiol. 2, 131-141. doi: 10.1046/j.1462-2920.2000.00078.x

Fischer, H. E. (1989). Origin of the "Weisse Schlesische Rübe" (white Silesian beet) and resynthesis of sugar beet. Euphytica 41, 75-80. doi: 10.1007/BF000 22414

Fürnkranz, M., Lukesch, B., Müller, H., Huss, H., Grube, M., and Berg, G. (2012). Microbial diversity inside pumpkins: microhabitat-specific communities display a high antagonistic potential against phytopathogens. Microb. Ecol. 63, 418-428. doi: 10.1007/s00248-011-9942-4 
Germida, J., and Siciliano, S. (2001). Taxonomic diversity of bacteria associated with the roots of modern, recent and ancient wheat cultivars. Biol. Fertil. Soils 33, 410-415. doi: 10.1007/s003740100343

Haichar, F. Z., Marol, C., Berge, O., Rangel-Castro, J. I., Prosser, J. I., Balesdent, J., et al. (2008). Plant host habitat and root exudates shape soil bacterial community structure. ISME J. 2, 1221-1230. doi: 10.1038/ismej.2008.80

Hardoim, P. R., Andreote, F. D., Reinhold-Hurek, B., Sessitsch, A., van Overbeek, L. S., and van Elsas, J. D. (2011). Rice root-associated bacteria: insights into community structures across 10 cultivars. FEMS Microbiol. Ecol. 77, 154-164. doi: 10.1111/j.1574-6941.2011.01092.x

Khan, M. (2013). "Update on sugarbeet diseases," in Crop and Pest Report. Available online at: http://www.ag.ndsu.edu/cpr/plant-pathology/ update-on-sugarbeet-diseases-08-22-13

Köberl, M., Müller, H., Ramadan, E. M., and Berg, G. (2011). Desert farming benefits from microbial potential in arid soils and promotes diversity and plant health. PLoS ONE 6:e24452. doi: 10.1371/journal.pone.0024452

Kropf, S., Heuer, H., Grüning, M., and Smalla, K. (2004). Significance test for comparing complex microbial community fingerprints using pairwise similarity measures. J. Microbiol. Meth. 57, 187-195. doi: 10.1016/j.mimet.2004. 01.002

Lambert, B., Meire, P., Joos, H., Lens, P., and Swings, J. (1990). Fast-growing, aerobic, heterotrophic bacteria from the rhizosphere of young sugar beet plants. Appl. Environ. Micobiol. 56, 3375-3381.

Lane, D. J. (1991). "16S/23S rRNA sequencing," in Nucleic Acid Techniques in Bacterial Systematics, eds E. Stackebrandt and M. Goodfellow (Chichester: John Wiley \& Sons), 115-175.

Latz, E., Eisenhauer, N., Rall, B. C., Allan, E., Roscher, C., Scheu, S., et al. (2012). Plant diversity improves protection against soil-borne pathogens by fostering antagonistic bacterial communities. J. Ecol. 100, 597-604. doi: 10.1111/j.13652745.2011.01940.x

Mendes, R., Kruijt, M., de Bruijn, I., Dekkers, E., van der Voort, M., Schneider, J. H. M., et al. (2011). Deciphering the rhizosphere microbiome for diseasesuppressive bacteria. Science 332, 1097-1100. doi: 10.1126/science.1203980

Peiffer, J. A., Spor, A., Koren, O., Jin, Z., Tringe, S. G., Dangl, J. L., et al. (2013). Diversity and heritability of the maize rhizosphere microbiome under field conditions. Proc. Natl. Acad. Sci. U.S.A. 110, 6548-6553. doi: 10.1073/pnas.13028 37110

Pester, M., Bittner, N., Deevong, P., Wagner, M., and Loy, A. (2010). A rare biosphere microorganism contributes to sulfate reduction in a peatland. ISME J. 4, 1591-1602. doi: 10.1038/ismej.2010.75

Philippot, L., Raaijmakers, J. M., Lemanceau, P., and van der Putten, W. H. (2013). Going back to the roots: the microbial ecology of the rhizosphere. Nat. Rev. Microbiol. 11, 789-799. doi: 10.1038/nrmicro3109

Reeder, J., and Knight, R. (2010). Rapid denoising of pyrosequencing amplicon data: exploiting the rank-abundance distribution. Nat. Methods 7:668. doi: 10.1038/nmeth0910-668b

Schwieger, F., and Tebbe, C. C. (1998). A new approach to utilize PCR-single strand conformation polymorphism for $16 \mathrm{~S}$ rRNA gene-based microbial community analysis. Appl. Environ. Microb. 64, 4870-4876.

Shannon, C. E. (1997). The mathematical theory of communication. 1963. M.D. Comput. 14, 306-317.
Shaw, B., Thomas, T. H., and Cooke, D. T. (2002). Responses of sugar beet (Beta vulgaris L.) to drought and nutrient deficiency stress. Plant Growth Regul. 37, 77-83. doi: 10.1023/A:1020381513976

Shi, Y., Yang, H., Zhang, T., Sun, J., and Lou, K. (2014). Illumina-based analysis of endophytic bacterial diversity and space-time dynamics in sugar beet on the north slope of Tianshan mountain. Appl. Microbiol. Biotechnol. 98, 6375-6385. doi: 10.1007/s00253-014-5720-9

Thrane, C., Harder Nielsen, T., Neiendam Nielsen, M., Sørensen, J., and Olsson, S. (2000). Viscosinamide-producing Pseudomonas fluorescens DR54 exerts a biocontrol effect on Pythium ultimum in sugar beet rhizosphere. FEMS Microbiol. Ecol. 33, 139-146. doi: 10.1111/j.1574-6941.2000.tb00736.x

Wang, Q., Garrity, G. M., Tiedje, J. M., and Cole, J. R. (2007). Naïve Bayesian classifier for rapid assignment of rRNA sequences into the new bacterial taxonomy. Appl. Environ. Microbiol. 73, 5261-5267. doi: 10.1128/AEM.00062-07

Weinert, N., Meincke, R., Gottwald, C., Heuer, H., Gomes, N. C., Schloter, M., et al. (2009). Rhizosphere communities of genetically modified zeaxanthinaccumulating potato plants and their parent cultivar differ less than those of different potato cultivars. Appl. Environ. Micobiol. 75, 3859-3865. doi: 10.1128/ AEM.00414-09

Weinert, N., Piceno, Y., Ding, G. C., Meincke, R., Heuer, H., Berg, G., et al. (2011). PhyloChip hybridization uncovered an enormous bacterial diversity in the rhizosphere of different potato cultivars: many common and few cultivar-dependent taxa. FEMS Microbiol. Ecol. 75, 497-506. doi: 10.1111/j. 1574-6941.2010.01025.x

Wissuwa, M., Mazzola, M., and Picard, C. (2009). Novel approaches in plant breeding for rhizosphere-related traits. Plant Soil 321, 409-430. doi: 10.1007/s11104008-9693-2

Zachow, C., Müller, H., Tilcher, R., Donat, C., and Berg, G. (2013). Catch the best: Novel screening strategy to select Stress Protecting Agents for crop plants. Agronomy 3, 794-815. doi: 10.3390/agronomy3040794

Zachow, C., Tilcher, R., and Berg, G. (2008). Sugar beet-associated bacterial and fungal communities show a high indigenous antagonistic potential against plant pathogens. Microb. Ecol. 55, 119-129. doi: 10.1007/s00248-0079257-7

Conflict of Interest Statement: The authors declare that the research was conducted in the absence of any commercial or financial relationships that could be construed as a potential conflict of interest.

Received: 01 October 2013; accepted: 22 July 2014; published online: 26 August 2014. Citation: Zachow C, Müller H, Tilcher R and Berg G (2014) Differences between the rhizosphere microbiome of Beta vulgaris ssp. maritima-ancestor of all beet cropsand modern sugar beets. Front. Microbiol. 5:415. doi: 10.3389/fmicb.2014.00415

This article was submitted to Plant-Microbe Interaction, a section of the journal Frontiers in Microbiology.

Copyright (C) 2014 Zachow, Müller, Tilcher and Berg. This is an open-access article distributed under the terms of the Creative Commons Attribution License (CC BY). The use, distribution or reproduction in other forums is permitted, provided the original author(s) or licensor are credited and that the original publication in this journal is cited, in accordance with accepted academic practice. No use, distribution or reproduction is permitted which does not comply with these terms. 